\title{
Secuenciamiento de los genes de las proteínas verde y roja flourescentes del pez cebra transgénico (Danio rerio) introducido al Perú
}

Sequencing of the genes of the fluorescent green and red proteins of
the transgenic zebrafish (Danio rerio) introduced to peru

\author{
Carlos SCOTto ${ }^{1,2}$ \\ Ricardo CHUAN ${ }^{2}$ \\ Julissa Mesía ${ }^{2}$ \\ LESLIE IGREDA ${ }^{2}$ \\ Mauro Quiñones ${ }^{2}$ \\ CÉsar Arriola ${ }^{3}$
}

\begin{abstract}
Resumen
En el año 2006 se identificó el primer movimiento transfronterizo de peces cebra fluorescentes al territorio peruano. Se tiene poco conocimiento del posible impacto ambiental ante la liberación descontrolada de estos peces transgénicos fluorescentes. Así como, los orígenes y flujo génico de estos organismos hidrobiológicos. Se analizó por PCR los genes de fluorescencia GFP (Proteína fluorescente verde) y RFP (Proteína fluorescente roja) en peces cebra transgénicos introducidos dentro del territorio peruano y de peces cebra procedentes de Colombia, Chile y de Taiwán como controles positivos. Todas las secuencias nucleotídicas correspondían a la proteína fluorescente roja (drFP583) de la anémona marina Discosoma sp. con un tamaño de 505pb (RFP) y de su variante verde (GFP) con un tamaño de $570 \mathrm{pb}$. Asimismo, el análisis filogenético evidenció un origen asiático del movimiento transfronterizo de estos peces por una ruta sudamericana vía Colombia principalmente hacia territorio peruano.
\end{abstract}

Palabras clave: GFP, RFP, pez cebra, fluorescencia, Discosoma, transfronterizo

\begin{abstract}
In 2006, the first transboundary movement of fluorescent zebrafish to the Peruvian territory was identified. Little is known about the possible environmental impact due to the uncontrolled release of these transgenic fluorescent fish. As well as, the origins and gene flow of these hydrobiological organisms. The fluorescence genes GFP (Green Fluorescent Protein) and RFP (Red Fluorescent Protein) in transgenic Zebrafish introduced into the Peruvian territory and Zebrafish from Colombia, Chile and Taiwan as positive controls were analyzed by PCR. All nucleotide sequences corresponded to the red fluorescent protein (drFP583) of the marine anemone Discosoma sp. with a size of $505 \mathrm{pb}$ (RFP) and its green variant (GFP) with a size of 570pb. Likewise, the phylogenetic analysis evidenced an Asian origin of the transboundary movement of these fish along a South American route via Colombia, mainly to Peruvian territory.
\end{abstract}

Key words: GFP, RFP, zebrafish, fluorescence, Dyscosoma, transboundary

(C) Los autores. Este artículo es publicado por la Revista Campus de la Facultad de Ingeniería y Arquitectura de la Universidad de San Martín de Porres. Este artículo se distribuye en los términos de la Licencia Creative Commons Atribución No-comercial - Compartir-Igual 4.0 Internacional (https://creativecommons.org/licenses/ CC-BY), que permite el uso no comercial, distribución y reproducción en cualquier medio siempre que la obra original sea debidamente citada. Para uso comercial contactar a: revistacampus@usmp.pe. 


\section{Introducción}

El 9 de diciembre del 2011, el Gobierno Peruano promulgó la Ley $\mathrm{N}^{\circ} 29811$ que establece la Moratoria al Ingreso y Producción de Organismos Vivos Modificados (OVM o transgénicos) destinados a la liberación intencional al ambiente por un periodo de 10 ańos. La finalidad de la ley es fortalecer las capacidades en bioseguridad, desarrollar la infraestructura requerida y generar las líneas de base que permitan una adecuada evaluación de las actividades de liberación de OVMs al ambiente. En ese escenario, se percibe que la producción y/o liberación de transgénicos atentaría contra la biodiversidad por el potencial riesgo de flujo genético no controlado y que afectaría al Perú como "Centro de origen o de Diversidad Biológica”.

Es importante decir que el Perú forma parte del Protocolo de Cartagena sobre Seguridad de la Biotecnología del Convenio sobre la Diversidad Biológica que regula los movimientos de Organismos Genéticamente Modificados (GMO) de un país a otro (CIISB/BCHPerú, 2015). Existe desde el año 2011 una Ley Moratoria en el Perú (Ley $\mathrm{N}^{\circ}$ 29811) a la liberaciónde cualquier OVM introducido $y / o$ producido basado en el Principio Precautorio ante la incertidumbre de si se puede producir daño ambiental o a la biodiversidad o no. Actualmente, la Ley $\mathrm{N}^{\circ} 27104$ habla sobre la prevención de riesgos derivados del uso de la biotecnología moderna referida a los OVM con la finalidad de prevenir, evitar o reducir los posibles efectos adversos para garantizar un nivel adecuado de protección para la salud humana, la diversidad biológica y el medioambiente de los OVM y sus productos derivados haciendo hincapié en los puntos controversiales como son su liberación al ambiente o el uso en ambientes confinados.

A principios del siglo XXI, se desarrollaron a nivel de laboratorio los primeros peces ornamentales transgénicos. La técnica para la obtención de estos OVM consistió en la introducción de genes que producen proteínas fluorescentes de colores verde (GFP, Green Fluorescent Protein), rojo (RFP, Red Fluorescent Protein), entre otros, extraídos primero de la medusa abisal Aequorea victoria (Murbach y Shearer, 1902) y luego de la anémona de mar [(Anemonia manjano (Carlgren,1900)] y otros organismos marinos (Gong et al., 2001; Wan et al., 2002; Udvadia \& Linney, 2003).

Los primeros peces transgénicos fluorescentes fueron diseñados como mascotas de acuario. Como el pez Medaka [Oryzias latipes (Temminck y Schlegel, 1846)] (Tanaka et al., 2001; Nguyen et al., 2014) y el pez cebra [Danio rerio (Hamilton,1822)] (Gong et al., 2003). Principalmente se desarrollaron para ser comercializados en los mercados de los Estados Unidos (http://www. glofish.com) y de Taiwán (http:// www.azoo.com.tw) respectivamente. Actualmente, se comercializan varias especies genéticamente modificadas de peces ornamentales fluorescentes dulceacuícolas en el mundo tales como: pez cebra [Danio rerio (Hamilton, 1822)]; el pez Monjita o Tetra [Gymnocorymbus ternetzi (Boulenger, 1895)]; el Barbo sumatrano [Puntius tetrazona (Bleeker, 1855)]; el pez Medaka japones [Oryzias latipes (Temminck y Schlegel, 1846)]; el pez ángel o Escalar [Pterophyllum scalare (Lichtenstein, 1823)]; el Cíclido convicto 
[Amatitlania nigrofasciata (Günther, 1867)]; el Neón chino [Tanichthys albonubes (Lin, 1932)] entre otros (Bielikova, 2012; Pan et al., 2008; Qing et al, 2012; Zhu \& Zon, 2004).

En el año 2006, se identificó el primer movimiento transfronterizo de peces cebra fluorescentes al territorio peruano (Scotto, 2011) (Figura 2). Posteriormente, se logró su reproducción e hibridación en cautiverio (Scotto, 2012). Y en el 2013, se logró la primera identificación de peces cebra con la proteína roja fluorescente de la anémona de mar [(Discosoma sp. (Forsskål, 1775)] en el Perú mediante el análisis de transgenes (Scotto \& Serna, 2013). En el año 2015, se obtuvieron otros peces fluorescentes transgénicos que salieron al mercado mundial en las especies: Puntius tetrazona y Epalzeorhynchos frenatum (Glofish, 2018).

En el año 2018 ya se reporta el segundo ingreso al territorio peruano de peces ornamentales Monjita o tetra transgénicos (Gymnocorymbus ternetzi) (Scotto,2018). En el año 2016, se comprobó el flujo génico de los transgenes GFP y RFP de los parentales a la progenie $\mathrm{F} 1$ en condiciones confinadas en el pez cebra (Scotto \& Chuan, 2018). Así mismo, se reportó la captura de peces cebra fluorescentes de color rojo liberados en la cuenca del río Amazonas en el departamento de Loreto (MINAM, 2016). Hoy en día, se tiene poco conocimiento del posible impacto ambiental ante la liberación descontrolada de estos peces transgénicos por la falta de un análisis de riesgos que evalué su flujo génico (Manzi, 2016).

En el Perú, existen zonas climáticas térmicamente muy semejantes a las zonas de origen de donde proceden la mayoría de estos peces exóticos (del Sudeste Asiático, de América Central y del Sur) y que podrían reproducirse y prosperar en estas zonas como son la costa norte del Perú (departamentos de Tumbes, Piura, La Libertad y Lambayeque). Y los departamentos con zonas selváticas donde la temperatura supera los $24^{\circ} \mathrm{C}$ como son: Cajamarca, Amazonas, San Martín, Junín, Huánuco, Pasco, Cuzco, Loreto, Ucayali y Madre de Dios (Scotto, 2016). El objetivo de este trabajo fue evidenciar molecularmente el flujo génico de los peces cebras transgénicos fluorescentes rojo y verde procedente del extranjero.

\section{Método}

\section{Materiales y métodos de identificación de la fluorescencia en peces cebra}

Se realizó confirmación de la presencia (Transgénico) o ausencia (No transgénico) de fluorescencia corporal mediante la exposición de cada pez ante la luz ultravioleta de un transiluminador de menos de $400 \mathrm{~nm}$ de longitud de onda por treinta segundos (Figura 1).

\section{Extracción de ADN de tejido muscular de pez cebra}

Se extrajo 200mg del músculo dorsal del pez y colocó en un tubo ependorff de $1.5 \mathrm{ml}$ estéril para ser procesado con el Kit de extracción de ADN gSYNCTM. Se agregó 0,5 volúmenes de agua libre de nucleasas y homogenizó con un mortero estéril. Se extrajo $50 \mathrm{ml}$ del sobrenandante y homogenizó según el protocolo del Kit DNeasy Blood \& Tissue. Finalmente se deluyó en 100ul de buffer de elución y sembró 3ul de buffer de carga 3X más 6ul de ADN extraído en cada pocillo del gel de agarosa. Las muestras fueron corridas 
en un gel de agarosa al $1.5 \%$ para observar la calidad del ADN extraído comparado con la banda de $23100 \mathrm{pb}$ del marcador de peso molecular Fago lambda digerido con Hind III (Figura 2).

\section{Amplificación por PCR de la GFP y RFP en peces cebra fluorescentes transgénicos}

La amplificación por PCR se trabajó con una concentración de 40ng/ul de cada muestra (Volumen final de 25ul): 14.3ul de agua libre de nucleasas, 5ul de buffer 5X Green Colorless Go Taq Flexi, $0.5 \mathrm{ul}$ de dNTPs $(25 \mathrm{~nm}), 0.5 \mathrm{ul}$ de primer GFP/RFP Forward o Reverse (10 $\mathrm{uM}), 0.2 \mathrm{ul}$ de polimerasa Go taq DNA $(5 \mathrm{u} / \mathrm{ul})$ y $0.2 \mathrm{ul}$ de muestra de ADN. Las condiciones de ciclaje para el PCR fueron las siguientes: Activación inicial de dos minutos a $95^{\circ} \mathrm{C}, 35$ ciclos de 30 segundos a $95^{\circ} \mathrm{C}, 30$ segundos a $62^{\circ} \mathrm{C}$ y minuto a $72^{\circ} \mathrm{C}$ seguido por una extensión final de cinco minutos a $72^{\circ} \mathrm{C}$. El producto amplificado fue analizado mediante una electroforesis en geles de agarosa al 1.5\%. Se utilizó un marcador de peso molecular de $100 \mathrm{pb}$ comercial. Los primers utilizados para identificar a los transgenes de GFP y RFP fueron los reportados por Bielikova et al. (2012) y Rehbein y Bogerd (2007) (Tabla 1). Se usó como controles negativos a peces cebra de color gris y blanco no fluorescentes.

Los amplificados de GFP (570 pb) y RFP (505 pb) purificados fueron enviados a secuenciar al extranjero.

Tabla 1

Secuencias de primers utilizados para identificar peces cebra transgénicos

\begin{tabular}{|c|c|c|c|c|}
\hline Gen & Nombre & Secuencia $\left(5^{\prime}-3^{\prime}\right)$ & $\begin{array}{l}\text { Tamaño } \\
\text { en pb }\end{array}$ & Referencia \\
\hline GFP & GFP1F & 5’-TCGAGCTGGACGGCGACGT-3’ & \multirow[b]{2}{*}{570} & \multirow{2}{*}{$\begin{array}{l}\text { Bielikova et al. } \\
\text { (2012) }\end{array}$} \\
\hline GFP & GFP1R & 5'-GGTGCTCAGGTAGTGGTTGTC-3' & & \\
\hline RFP & $\begin{array}{c}\text { RFP/ } \\
\text { Rerio2006 }\end{array}$ & 5’-ACAACACCGTGAAGCTGAAGGTGACCAAG-3' & \multirow{2}{*}{505} & \multirow{2}{*}{$\begin{array}{l}\text { Rehbein \& Bogerd } \\
\qquad(2007)\end{array}$} \\
\hline RFP & $\begin{array}{c}\text { RFP/ } \\
\text { Rerio2006 }\end{array}$ & 5'-GGTGTAGTCCTCGTTGTGGGAGGTGATGTC-3' & & \\
\hline
\end{tabular}

\section{Análisis molecular de las secuencias de GFP y RFP}

Con la información molecular se editó y alineó las secuencias con el programa Bioedit (Versión 7.0.4, 2005) y se construyó el árbol filogenético con el programa MEGA X (Kumar et al., 2018). Se comparó la secuencia nucleotídica del GFP de 573 nucleótidos de dos peces cebras fluorescentes verdes (Uno de Perú y otro de Colombia) con la secuencia del pez Medaka fluorescente verde importado de Taiwán como control positivo. Asimismo, se comparó las secuencias nucleotídicas del RFP de 482 nucleótidos de dos peces cebras (Uno de Perú y otro de Colombia) con el RFP secuenciado del pez cebra importado de Taiwán como control positivo.

\section{Resultados y discusión}

En la Figura 1, se observa peces cebra fluorescentes de color verde y rojo en contraste con el pez cebra de color blanco no transgénico. Se evidencia la fluorescencia ante luz UV. 


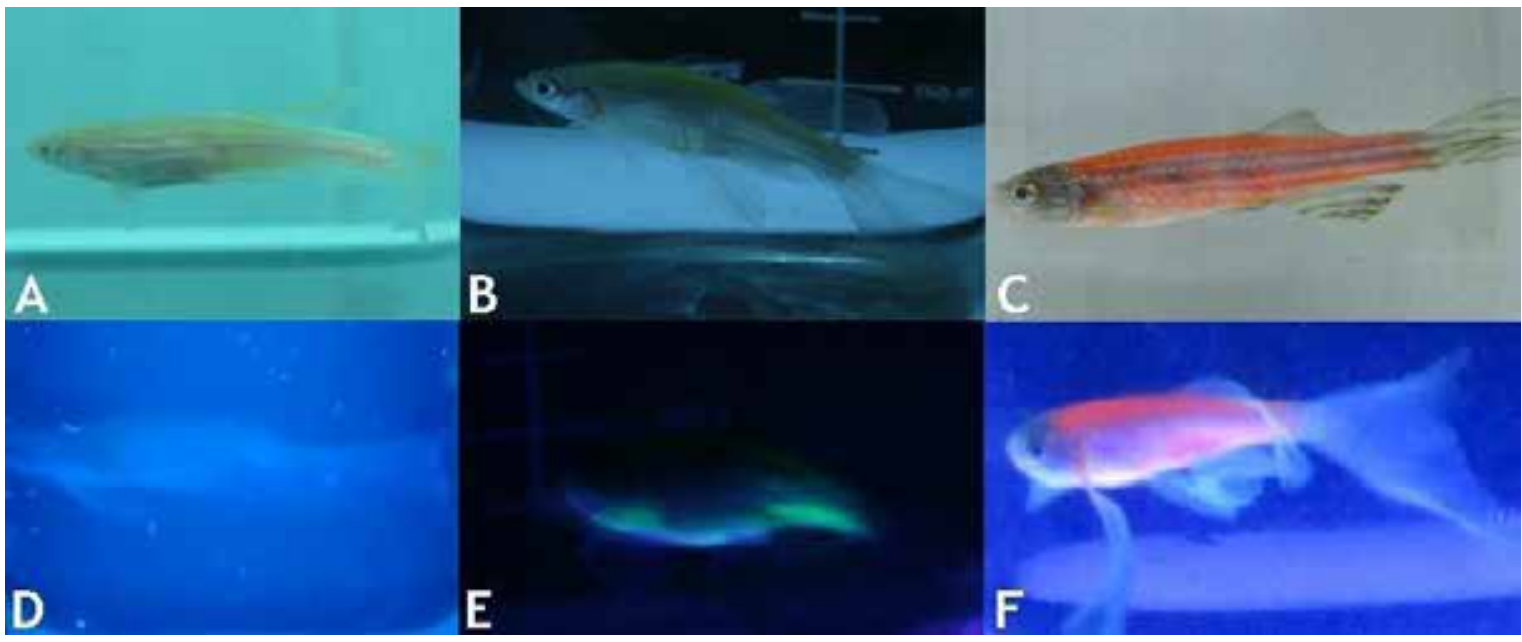

Figura 1. Peces Cebras (Danio rerio) con luz natural. $\mathrm{A}=$ Línea blanca no transgénica. $\mathrm{B}=$ Línea verde fluorescente. $\mathrm{C}=$ Línea roja fluorescente. Peces Cebras (Danio rerio) ante luz UV. A = Línea blanca no transgénica. $\mathrm{B}=$ Línea verde fluorescente. $\mathrm{C}=$ Línea roja fluorescente.

En la Figura 2, se observa la calidad fluorescentes de color verde y rojo pues del ADN extraído de los peces cebra solo se evidencia una sola banda.

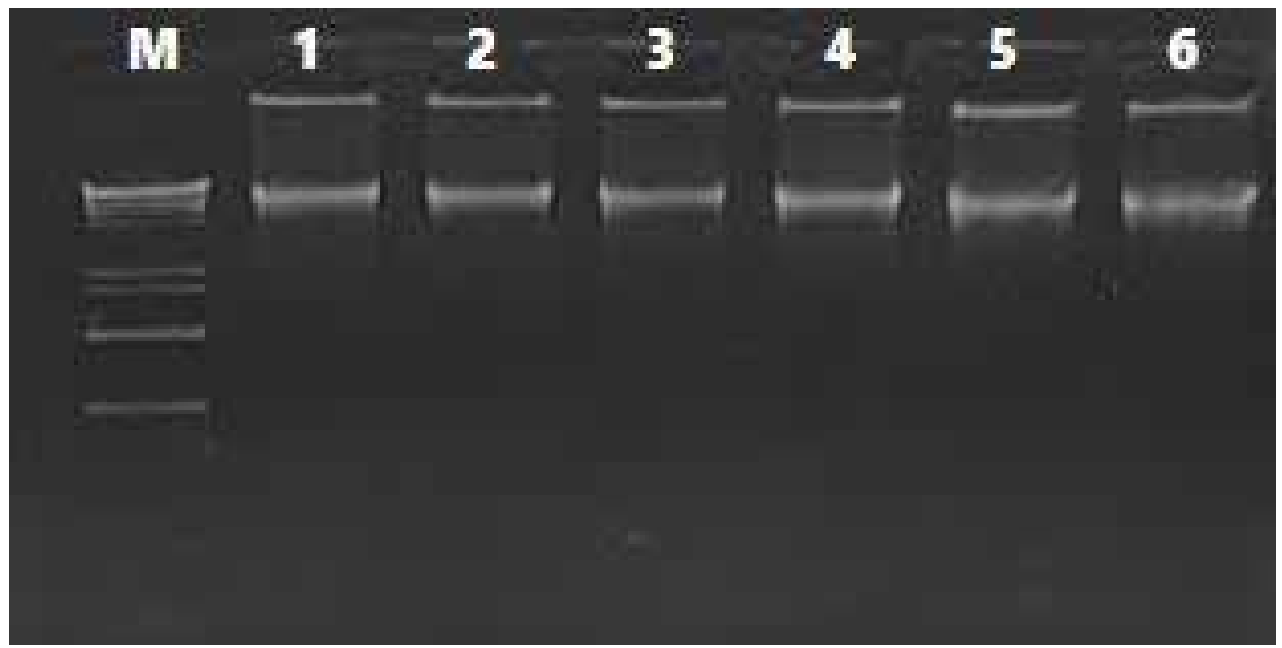

Figura 2. Gel de la Calidad del ADN extraído de pez cebra (Danio rerio) fluorescentes. Carriles 1, 2 y 3 = Peces cebra verde (GFP). Carriles 4, 5 y 6 = Peces cebras rojos (RFP). $\mathrm{M}=$ Marcador de peso molecular Fago lambda digerido con Hind III.

En la Figura 3, se observa las bandas del ADN amplificadas para identificar los transgenes de la proteína verde fluorescente (GFP) y la proteína roja fluorescente (RFP) de los peces cebra fluorescentes de color verde y rojo respectivamente. Los peces cebra de color gris y blanco no evidenciaron ninguna banda amplificada. 


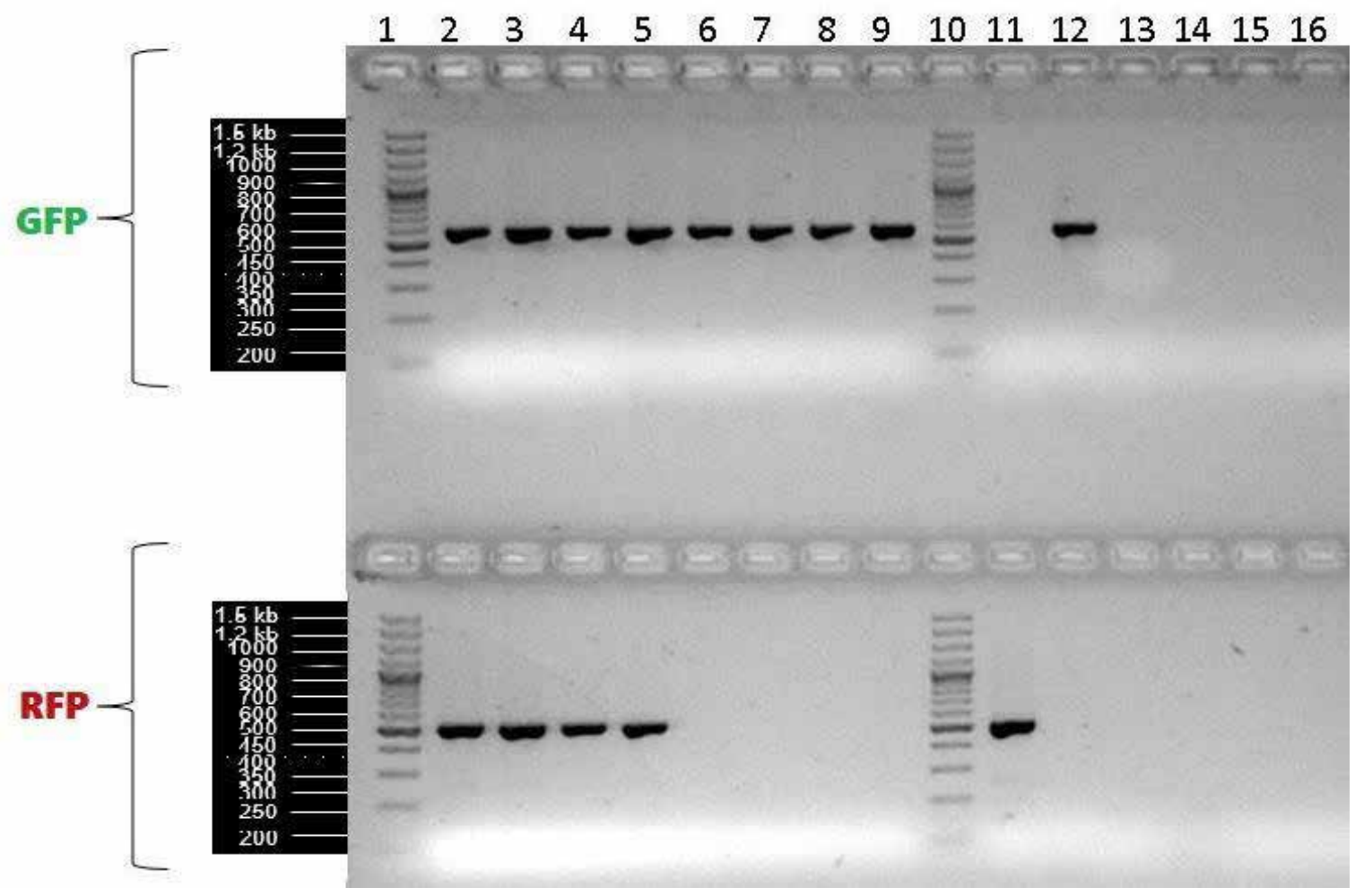

Figura 3. Gel de amplificado de pez cebra (Danio rerio). Carril 1 y $10=$ Marcador de peso molecular de 100 pb. Carriles 2 y 3 = Pez cebra transgénico de color rojo importado de Chile (RFP). Carriles 4 y 5 = Pez cebra transgénico de color rojo de Perú (RFP). Carril 6 y 7 = Pez cebra transgénico de color verde (GFP) importado de Colombia. 8 y 9 = Pez cebra transgénico fluorescentes de color verde (GFP) de Perú. Carril 11 = Pez cebra transgénico de color rojo de Taiwán (Control positivo de RFP). Carril 12 = Pez Medaka transgénico de color verde de Taiwán (Control positivo de GFP). Carriles 13 y 14 = Pez cebra gris no fluorescente (Control negativo). Carril 15 = Pez cebra blanco no fluorescente (Control negativo). Carril $16=$ Control de reactivos de amplificación por PCR.

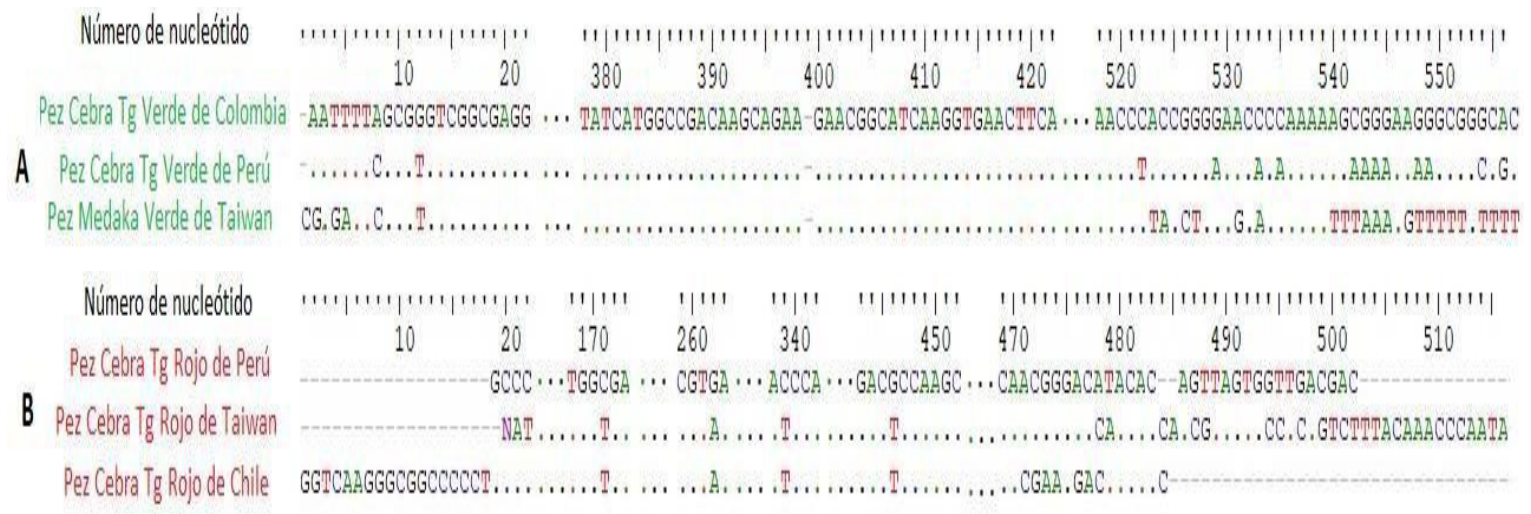

Figura 4. Análisis múltiple de las secuencias nucleotídicas alineadas (Programa Bioedit, 2005). A. Secuencias de la proteína Fluorescente Verde (GFP). B. Secuencias de la proteína fluorescente roja $(\mathrm{RFP}) . \mathrm{Tg}=$ Transgénico.

El alineamiento de las secuencias nucleotídicas de GFP y de RFP mostraron mucha similitud entre sí. Así para la proteína GFP la similaridad fue mayor entre los peces cebra de Perú y Colombia cuyo valor fue de $97.4 \%$ que 
con respecto al pez Medaka de Taiwán que fue de $96 \%$.

Para la proteína RFP la similaridad fue mayor entre los peces cebra de Perú y de Taiwán de $93.9 \%$ que con respecto al pez cebra de Chile que fue de $91.2 \%$. En la Figura 5, se observa el árbol filogenético obtenido de las secuencias de la GFP en el pez cebra fluorescente verde (Control pez Medaka fluorescente verde de Taiwán).
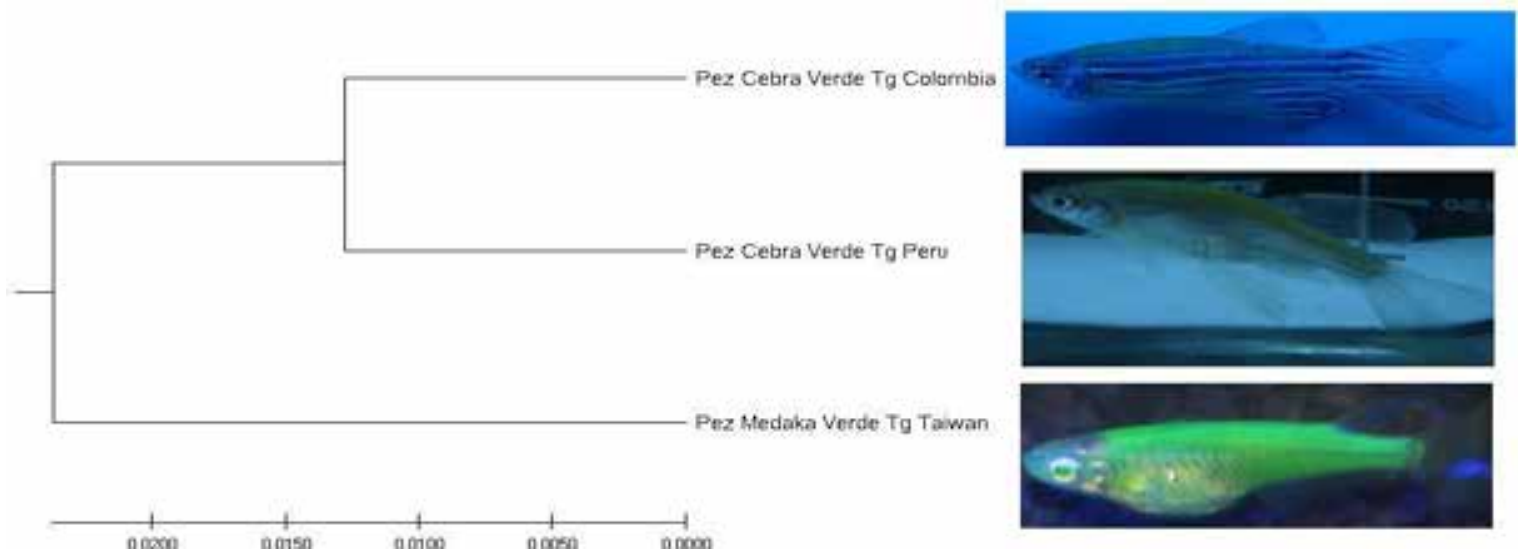

Figura 5. Árbol filogenético obtenido de las secuencias de la GFP de los peces cebra fluorescentes verdes del Perú y de Colombia (Control positivo = Pez Medaka fluorescente verde con GFP de Taiwán).

En la Figura 6, se observa el árbol filogenético obtenido de las secuencias de la RFP en el pez cebra fluorescente rojo

(Control pez cebra fluorescente rojo de Taiwán).

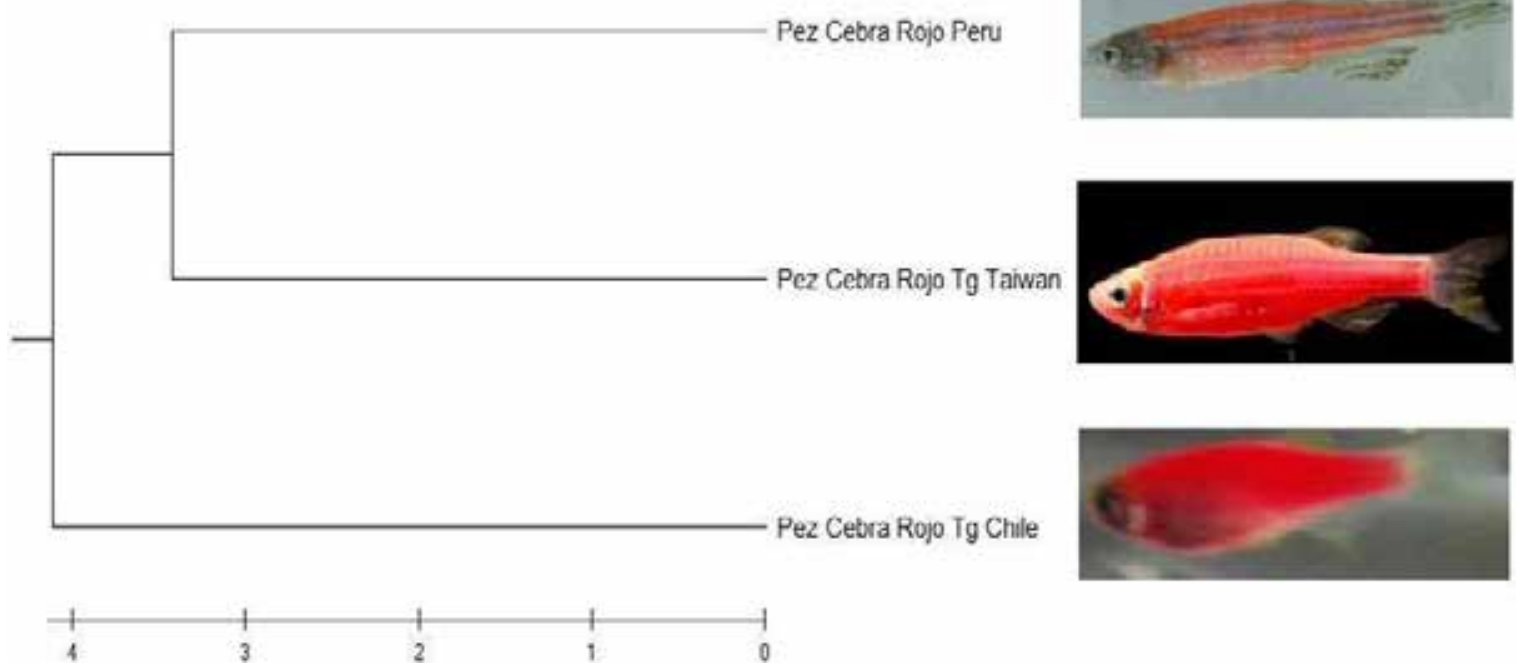

Figura 6. Árbol filogenético obtenido de las secuencias de la GFP de los peces cebra fluorescentes rojos del Perú y de Chile (Control positivo = Pez cebra fluorescente rojo de con RFP de Taiwán).

Si bien la tecnología basada en la inserción de proteínas fluorescentes de "Colores vivos" para generar nuevas variedades o líneas de diversos peces ornamentales transgénicos estables y cuyo auge es creciente en el acuarismo 
mundial actualmente. Las publicaciones científicas de ellos son muy escasas o no están disponibles sus secuencias y transgenia por lo que la estandarización de la tecnología sobre el tipo de constructor utilizado y el mecanismo de introducción de los transgenes fluorescentes no es de dominio público. Lo cual dificulta el empleo de métodos de detección molecular estandarizados de los mismos y poder así generar una vigilancia y fiscalización efectiva sobre la liberación accidental o deliberada de estos organismos hidrobiológicos modificados por ingeniería genética. En el presente trabajo se logró evidenciar la fluorescencia verde (GFP) y roja (RFP) de los peces cebras fluorescentes de los no transgénicos de las líneas gris y blanca ya reportado previamente por diversos autores (Ofelio et al., 2012; Tonelli et al., 2017) (Figura 1).

El proceso de extracción de $\mathrm{ADN}$ fue bueno evidenciándose solo una banda detallada para el proceso de amplificación por PCR. Todas las muestras de peces cebras (Danio rerio) de color rojo fluorescentes dieron positivo para el transgen de la proteína fluorescente roja (RFP) con una secuencia de una longitud de $505 \mathrm{pb}$. Asimismo, todas las muestras de peces cebras (Danio rerio) de color verde fluorescentes dieron positivo para el transgen de la proteína fluorescente verde (GFP) con una secuencia de una longitud de 570pb (Figura 2).

Se logró identificar los mismos transgenes de GFP y RFP en peces cebras reportados por Bielikova et al. (2012) y Rehbein y Bogerd (2007) (Figura 3). Sin embargo, todas las muestras de peces cebras (Danio rerio) de color rojo fluorescentes de Chile y Perú dieron positivo para el transgen de la proteína fluorescente verde (GFP). Lo cual indicaría procesos de cruzamiento entre estas dos líneas transgénicas.

De los resultados de los análisis filogenéticos de la Figuras 4 y 5, se puede concluir que el movimiento transfronterizo de estas especies ornamentales tendría una procedencia desde el continente asiático (Taiwán, China, Singapur). Esta ruta asiática vendría a países donde no está prohibida su importación como Colombia y Ecuador. Y desde ahí pasan a territorio peruano, llegan al norte del Perú (Lambayeque y La Libertad) y departamentos de la selva (San Martín, Loreto). Aquí los acuaristas peruanos los reproducen en grandes lotes de animales puros o cruzados para ser distribuidos a la capital Lima y otros departamentos alejados como Arequipa, Cuzco, Puno y Tacna donde han sido reportados. Y desde ahí serían exportados a países vecinos sudamericanos como Chile, Bolivia y probablemente a Argentina donde ya han sido reportados (Sernapesca de Chile, comunicación personal).

La tendencia mundial es incrementar el número de especies ornamentales transgénicas y con nuevos colores fluorescentes. Estas especies serán cada vez más vistosas y grandes en tamaño corporal donde el color "bioluminiscente" resalte más en un acuario. Económicamente el mayor precio por un pez fluorescente le otorgará mayores ganancias al criador $\mathrm{o}$ acuarista lo que crea un mercado muy rentable. A pesar de existir leyes y/o normativas que buscan regularlo, pero sin mucho éxito. 


\section{Conclusiones}

Las muestras de peces cebras (Danio rerio) de color rojo fluorescentes dieron positivo para el transgen de la proteína fluorescente roja (RFP) con una secuencia de una longitud de 505pb. Asimismo, todas las muestras de peces cebras (Danio rerio) de color verde fluorescentes arrojaron positivo para el transgen de la proteína fluorescente verde (GFP) con una secuencia de una longitud de 570pb. Las muestras de peces cebras (Danio rerio) de color rojo fluorescentes dieron positivo para el transgen de la proteína fluorescente verde (GFP). Probablemente, existe cruzamiento indiscriminado entre ambos tipos de peces cebra transgénicos (rojos y verdes). A pesar de que la fluorescencia se muestra solo el color rojo en el cuerpo del animal. Las secuencias de RFP y GFP poseen mucha similitud en su secuencia nucleotídica y corresponderían a la proteína fluorescente Roja (drFP583) de la anémona marina Discosoma sp. (Genbank No. Q9U6Y8.1). Del análisis filogenético los resultados para el gen de la GFP evidenciaron mucha homología molecular entre los peces cebras fluorescentes verdes de Perú y de Colombia. Se puede deducir el movimiento transfronterizo de estos peces a territorio peruano. Para el gen de la RFP evidenciaron mucha homología molecular entre los peces cebras fluorescentes rojos de Perú y de Taiwán. Se supone un movimiento transfronterizo desde países asiáticos productores de peces ornamentales fluorescentes rumbo a Perú, pero pasando primero por la ruta Sudamérica (Ecuador y Colombia) al territorio peruano debido a la ley de la moratoria que prohíbe su importación. Caso que no pasaría con Chile, donde el ingreso podría ser directamente de importaciones de países asiáticos a dentro de su territorio sin necesariamente cruzar territorio peruano.

\section{Referencias}

Azoo. (2017). En: http://www.azoo.com. tw leído el 01 de diciembre del 2015.

Bielikova, M.; Bukovska, G.; Vavrova, S.; Timko, J. \& Turna, J. (2012). Identificación de pez cebra (Danio rerio) genéticamente modificado por métodos de PCR. En: http://gmoglobalconference.jrc. ec.europa.eu/ Posters.htm PDF leído el 20 de noviembre de 2015.

BioEdit (2005). Versión 7.0.4. Copyright (C) 1997-2005, Tom Hall. En: http://www.mbio.ncsu.edu/ BioEdit/bioedit@.html
Centro de Intercambio de Información Sobre Bioseguridad del Perú (CIISB/BCH- Perú). En: http:// pe.biosafetyclearinghouse.net/ leído el 10 de Setiembre de 2018.

GloFish, (2017). Experience the Glo! En: http://www.glofish.com leído el 01 de diciembre del 2015.

Gong, Z., Ju, B. \& Wan, H. (2001). Green fluorescent protein (GFP) transgenic fish and their applications. Genetica. Vol. 111:213-225. DOI: $10.1023 / \mathrm{a}$ : 1013796810782 
Gong, Z.; Wan, H.; Leng Tay, T.; Wang, H.; Chen, M. \& Yan, T. (2003). Development of transgenic fish for ornamental and bioreactor by strong expression of fluorescent proteins in the skeletal muscle. Biochemical and Biophysical Research Communications, 308: 58- 63. DOI: 10.1016 / s0006$291 x(03) 01282-8$

Hall, T.A. (1999). BioEdit: a user-friendly biological sequence alignment editor and analysis program for Windows 95/98/NT. Nucleic Acids Symposium Series 41:95-98. DOI: 10.12691 / ajmr-2-6-8.

Kumar, S., Stecher, G. Li,M., Knyaz, C. \& Tamura, K. (2018). MEGA X: Molecular Evolutionary Genetics Analysis across Computing Platforms. Mol. Biol. Evol. 35(6):1547-1549. DOI: 10.1093 / molbev / msy096

Ley de Prevención de Riesgos Derivados del uso de la Biotecnología (Ley No 27104, 1999, Mayo 12). Diario Oficial El Peruano, pp. 173055. En: http://www.senasa.gob.pe/senasa/ wp-content/uploads/jer/DIR_ NOR_CUAV EG/00 072. PDF leído 20 de noviembre de 2019.

Ley que establece la moratoria al ingreso y producción de organismos vivos modificados al territorio nacional por un período de 10 años (Ley No 29811, 2011, Diciembre 09). Diario Oficial El Peruano, pp. 454601. En: http://minagri.gob.pe/ portal/download/pdf/marcolegal/ normaslegales/leyes/ley29811_ley_ prod _organismos_vivos.pdf leído
20 de noviembre de 2017. PDF leído 20 de noviembre de 2019.

Manzi, M. C. (2016). ¿Por qué producir peces transgénicos? Beneficios y riesgos. Tesis para optar el grado de Doctor. Universidad de la Republica, Facultad de Veterinaria. Montevideo, Uruguay. 84pp. En: https://www.colibri. udelar. edu.uy/jspui/bitstream/20. 500.12008/10385/1/FV-32140. pdf

MINAM. (2016). Servicio de consultoría para la prospección, distribución y análisis socioeconómico de peces ornamentales en las regiones de Loreto y Ucayali. Contrato $\mathrm{N}^{\circ}$ 039-2016-MINAMOGA. pp 97-98. En: http:// genesperu.minam.gob.pe/wpcontent/uploads/2016/09/ PO 2 - Prospecci $\%$ C 3\%B 3 ndistribuci\%C3\%B3n-y-analisissocio eco nomico-de-peces-O-enLoreto-y-Ucayali.pdf

Nguyen Tanh, Vu., Young Sun, Cho., Sang Yoon, Lee., Dong Soo, Kim. \& Yoon Kwon, Nam. (2014). Cyan Fluorescent Protein Gene (CFP)Transgenic marine medaka Oryzias dancena with potential ornamental applications. Fisheries and Aquatic Sciences, 17(4): 479-486. DOI: 10.5657 / FAS.2014.0479

Ofelio, C., Cariani, A., Trentini, M. \& Guarniero, I. (2012). Novel PCRbased assay for rapid identification of Red Fluorescent Proteins in GloFish and GloFish $\mathrm{x}$ wildtype zebrafish (Danio rerio) hybrids. Italian Journal of Zoology, 79:4, 
541-546. En: https://doi.org/10.1 080/11250003.2012.718805

Pan, X., Zhan, H. \& Gong, Z. (2008). Ornamental Expression of Red Fluorescent Protein in Transgenic Founders of White Skirt Tetra (Gymnocorymbus ternetzi). Marine Biotechnology, 10:497-501. DOI: 10.1007 / s10126-008-9094-9

Qing, J.; Chen, M.; Bai, D.; Jiang, P.; Fan, J.; Ye, X. \& Xia, S. (2012). Generation and characterization of a stable red fluorescent transgenic Tanichthys albonubes line. African Journal of Biotechnology, 11:77567765. DOI: $10.5897 / A J B 11.3273$

Rehbein, H. \& Bogerd, J. (2007). Identification of Genetically Modified Zebrafish (Danio rerio) by Protein- and DNA-Analysis. Journal fur Verbracherschutz und Lebensmittelsicherheit. 2: $122-$ 125. En: https://doi.org/10.1007/ s00003-007-0179-6

Scotto, C. (2011). Peces transgénicos fluorescentesenelPerú:Bioseguridad y análisis de riesgos pendientes. The Biologist (Lima) 8: 235-243. En: https://www.researchgate.net/ publication/277267274_Peces_ transgenicos_fluorescentes_e n_el_ peru_bioseguridad_y_analisis_de_ riesgos_pendientes

Scotto, C. (2012). Nota Científica: Reproducción e hibridación de peces transgénicos fluorescentes en cautiverio: Un alcance prospectivo. Scientia Agropecuaria 3(1):89-93. DOI: http://dx.doi.org/10.17268/ sci.agropecu.2012.01.11
Scotto, C. \& Serna, F. (2013). Primera identificación molecular del transgén de la proteína fluorescente roja (RFP) en peces cebra (Danio rerio) transgénicos ornamentales introducidos en el Perú. Scientia Agropecuaria 4: 257-264. DOI: 10.17268/sci. agropecu.2013.03.12

Scotto, C. (2016). Nota científica: Una casuística de peces transgénicos fluorescentes (Danio rerio) liberados en ambientes naturales peruanos con condiciones térmicas similares a su centro de origen. The Biologist 14 (1):129-141. En: http://dx.doi. org/10.24039/rtb201614193. ISSN: 1994-9073

Scotto, C. \& Chuan, R. (2018). Cruzamiento y flujo génico de los transgenes de las proteínas fluorescentes roja (RFP) y verde (GFP) en el pez cebra transgénico (Danio rerio) introducido al Perú. Aceptado para publicación en la revista Scientia Agropecuaria. Scientia Agropecuaria. Vol. 9(3):417-421. En: http:// dx.doi.org/10.17268/sci . agropecu.2018.03.13.

Tanaka, M., Kinashita, M., Kobayashi, D. \& Nagahama, Y. (2001). Establisment of Medaka (Oryzias latipes) transgenic lines with the expression of green fluorescent eclusive in germ cells: useful model to monitor germ cells in a live vertebrate. Proceedings of the National Academy of Sciences of the United States of America, 98: 2544-2549. DOI:10.1073 / pnas. 041315498 
Tonelli, F., Lacerdac, S., Tonellia, F., Costac, G., Renato de Françac, L. \& Resendea, R. (2017). Progress and biotechnological prospects in fish transgénesis. Biotechnology Advances 35:832-844. DOI: $10.1016 / \mathrm{j}$. biotechadv.2017.06.002

Udvadia, A. \& Linney, E. (2003). Windows into development: historic, current, and future perspectives on transgenic zebrafish. Developmental Biology, 256: 1-17. En: https://doi.org/10.1016/ S0012-1606(02)00083-0

Uma, B. \& Chandran, M. (2009). First report on the karyology of Gymnocorymbus ternetzi (Boulenger). Research Journal of Cell and Molecular Biology, 3, 113-115.

Wan, H., He, J., Ju, B., Yan, T., Lam, T.J., \& Gong, Z. (2002). Generation of Two-color Transgenic Zebrafish Using the Green and Red Fluorescent Protein Reporter Genes GFP and RFP. Marine Biotechnology, 4:146-54. DOI: 10.1007 / s10126-001-0085-3

Zhu, H. \& Zon, L. (2004). Use of the DsRed fluorescent reporter in zebrafish. Methods in Cell Biology, 76:3-12. DOI: 10.1016 / s0091679x (04) 76001-x 